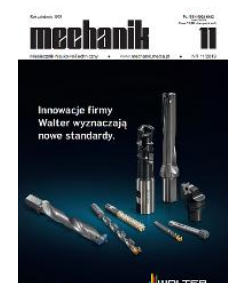

How to cite this article:

Authors: Paweł Turek, Wacław Skoczyński, Marek Stembalski

Title of article: „Controlling the preload adjustment system of bearings in the machine spindle model using the

LabVIEW environment"

Mechanik, No. 11 (2019)

DOI: https://doi.org/10.17814/mechanik.2019.11.92

\title{
Controlling the preload adjustment system of bearings in the machine spindle model using the LabVIEW environment
}

\author{
PAWEL TUREK \\ WACŁAW SKOCZYŃSKI \\ MAREK STEMBALSKI *
}

\begin{abstract}
* Dr inż. Paweł Turek, pawel.turek@pwr.edu.pl, https://orcid.org/0000-0001-7522-2116 - Katedra Obrabiarek i Technologii Mechanicznych, Wydział Mechaniczny, Politechnika Wrocławska, Wrocław, Polska

Dr hab. inż. Wacław Skoczyński prof. PWr, waclaw.skoczynski@pwr.edu.pl, https://orcid.org/0000-0002-7215-7037 - Katedra Obrabiarek i Technologii Mechanicznych, Wydział Mechaniczny, Politechnika Wrocławska, Wrocław, Polska

Dr inż. Marek Stembalski, marek.stembalski@pwr.edu.pl, https://orcid.org/0000-0002-0801-690X - Katedra Obrabiarek i Technologii Mechanicznych, Wydział Mechaniczny, Politechnika Wrocławska, Wrocław, Polska
\end{abstract}

The test stand with a high-speed spindle equipped with active support, which provides the possibility of changing the preload of the bearings, was presented. The LabVIEW software environment was used for control. Benefits resulting from the use of the active system to reduce the amplitude of the vibration displacement of the spindle tip were presented.

KEYWORDS: machine tool, angular contact bearing, preload, LabVIEW environment, real-time control

\section{Introduction}

Modern machine tools are equipped with mechatronic systems. Their purpose is to affect the machine properties during machining [7]. One of the many applications areas of those systems are machine tool spindles. In the literature can be found a lot of examples $[4,6,9]$ of using the mechatronic solutions for change of the bearing nodes preload value. With these additional systems, it is possible to considerably expand spindle working range, actively influence for its parameters [3] and spindle dynamic properties.

An important parameter of turning tool spindles is rigidity [8]. Machining centres often use electro spindles as main drives, and bearing system of these spindles is based on contact ball bearings. They are able to carry the load both radial forces and axial forces, and for correct operation need appropriate preload. This value determines spindle operating parameters, mainly its rigidity.

If bearings run with light [5] preload obtains small spindle rigidity, which enables machining smaller material allowance, but with high rotational speed. In the case of heavy preload obtains the inverse to these correlations. The use of an active system for preload change allows to spindle rigidity change and better preload fitting defending on short-time needs of the machining process.

\section{Test stand}

A stand consists of individually designed and performed spindle with active support was developed. It was assumed that due to type, distribution and bearings operation, spindle system shall be characteristic of electric grinding spindle. For its bearings was used single angular contact ball bearings B7206-CT-PS4-UM from FAG, working in "O" system. Spindle did not have the typical end allows mounting cutting tool, but only possibility to settle the substitute mass, which simulate the grinding wheel.

In active support to change preload was used three commercial piezo actuators (fig. 1 - 5). The principles of their operation are based on so-called reverse piezoelectric effect. It is about dimensions change of stack of 
piezo elements influenced by electrical voltage. Voltage was generating from three channel amplifier SVR 150/3 from Piezomechanik GmbH, may work in loop feedback. Before installing, every piezo actuator was calibrated on a separate stand. Hysteresis and characteristics for its entire extension range $(0 \div 55 \mu \mathrm{m})$ was determined.

Piezo actuator distribution was symmetrical on the diameter $\varnothing 60 \mathrm{~mm}$ along the spindle axes. Attachment ensures axial adjustment of their position. Owing to this and using strain gauge system located inside the active elements we obtained assurance that every piezo actuator presses on the outer bearing race with the same force.

To control of bearing operation, three contact position sensors was installed in active support (6), thanks to which it was possible the ongoing monitoring the relative axial movements of the outer bearing race. The space between bearing support in the spindle model was assumed as $154 \mathrm{~mm}$. This value has been limited to the minimum, that the thermal elongation of the spindle shaft $[1,11]$ can be considered negligible and does not cause additional errors. For system spindle drive was used three-phase induction motors (4) with frequency converters (from Siemens), which allowed for smooth regulation of the engine speed in the range $0 \div 24,000 \mathrm{rev} / \mathrm{min}$. Backlash-free caw couplings drives the spindle (3).

The engine was placed at additional plate equipped with adjustable foots to ensure its correct setting in relation to the spindle. The alignment procedure carried out using modern measurement system E 710 (from Easy Laser).

The complete test stand additionally included: measurement amplifier type QuantumX MX840 (from HBM), measurement chart NI 9264 (from National Instruments; used to setting the rotational speed control signals and piezo-actuators extension) and computer PC with own application, which enable measurement performance, results recording and test stand system control.



Fig. 1. The schematic diagram of the tested spindle with a drive motor: 1 - front support, 2 - rear support, 3 - ROTEX clutch from KTR, 4 - high speed C5160D-DB-PER32 drive motor from Teknomotor, 5 - piezoactuator PSt 150/10/40 VS15 by Piezomechanik, 6 - MDKa - F1 displacement sensor from VIS

\section{Working conditions of spindle with active support and preliminary tests}

The main purpose of the test was to check, if the use of active support and adjustment of bearing preload could reduce the displacement amplitude of the spindle tip subjected to harmonic excitation. Grinding spindles usually are equipped with grinding wheel placed on forward tip. Its mass has significant impact on mass distribution in entire spindle and changes the amplitude-frequency characteristics of given system.

Spindle model was tested. To provide close to real working conditions, at its forward end was placed by additional bearing replacement mass around $1.5 \mathrm{~kg}$ (fig. 2-5). On the test stand is installed inductor (1), with through replacement mass has forced excitation of examined system by signal with determined parameters. The contact-free inductive sensor (6) was used for measuring of vibration displacement of spindle forward end. Tested spindle during measurements is shown in fig. 2.

The forcing signals was generated directly by soundcard of PC computer using random functions. This has provided signals with different lengths of time in the frequency band of $0 \div 3 \mathrm{kHz}$.

At the beginning to determine the spindle characteristics, forcing signal was supplied to input of excitation inductor amplifier type PA 100E from Data Physics. At this stage, replacement mass was placed directly at the spindle end, without additional bearing. For such system, a linear sweep was carried out, in which the signal frequency increased or decreased in proportion to the time. The vibrations were recorded by piezoelectric acceleration sensors type 4384 form Brüel\&Kjaer, which by measuring chart type NI PXI - 4472 collected 
amplitude-frequency characteristics of spindle model. The data was recorded on specialised measurement computer PXI from National Instruments. In this way, the values of amplitudes and resonance frequencies in the full range of bearing preload values $(60 \div 430 \mathrm{~N})$ allowed by their manufacturer were determined.

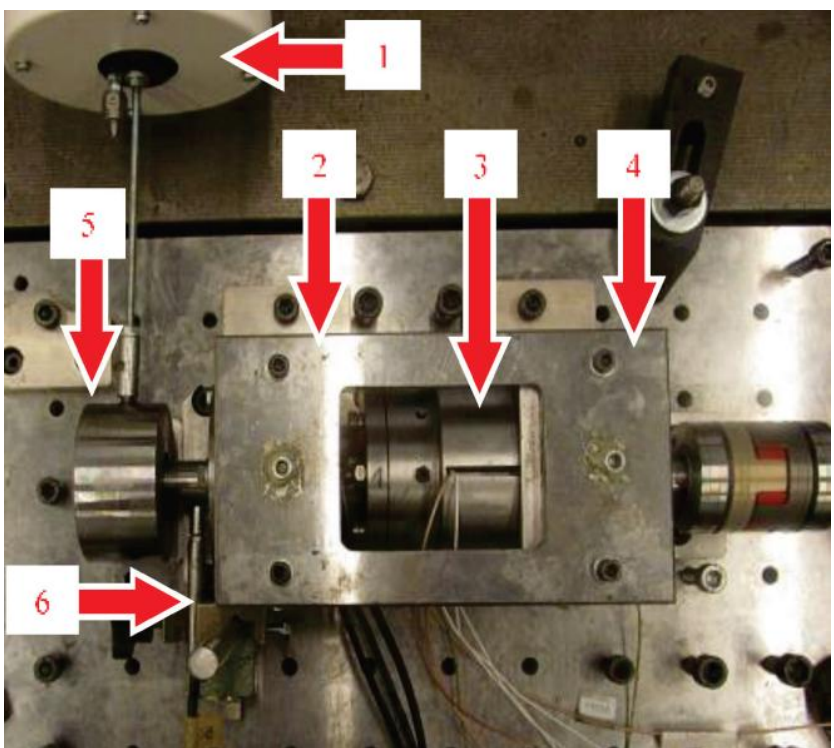

Fig. 2. Test stand during measurements with the use of active preload adjustment: 1 - GW - V20 inductor for forcing the vibration of the tested spindle from Data Physics, 2 - front support, 3 - active tension module, 4 - rear support, 5 - replacement mass, 6 - non-contact displacement sensor

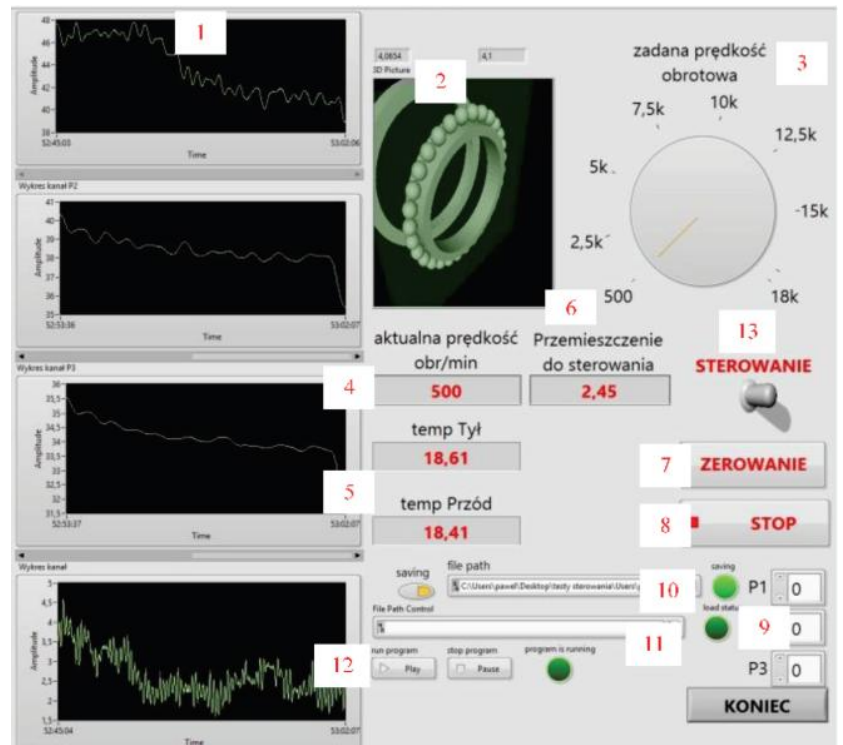

Fig. 3. LabVIEW front panel for controlling applications and measuring spindle properties: 1 - measuring windows for monitoring displacements on individual touch sensors (autoscaled range), 2 - visualization of bearing operation in the active support, 3 - rotary speed setting knob, 4 - reading the spindle speed, 5 - reading temperatures on individual bearing supports,

6 - additional measuring windows used for testing the axial and radial rigidity of the spindle, 7 - zeroing inductive displacement sensors, 8 - stopping the application, 9 - actuator displacement adjuster, 10 - selection of the place to save measurement data, 11 - introduction of the function controlling the spindle system, 12 - buttons for starting speed control

After a preliminary study has been stated that the variation range of the system basic resonance frequency is in the range $190 \div 290 \mathrm{~Hz}$. In order to obtain more accurate results, frequency range of linear sweep is limited to $150 \div 450 \mathrm{~Hz}$. The single test time was established at $120 \mathrm{~s}$, and sampling frequency - at $3,000 \mathrm{~Hz}$.

To measure spindle operating parameters and to control the entire spindle system have been developed application based on environment LabVIEW. It allows for supervising the test stand work, readings its parameters, recording the most important data and active support system control (fig. 3).

\section{Control algorithm}

Measurements carried out for a narrower frequency range confirmed the close relation between the bearing preload and basic resonance frequency and the level of vibration amplitude of the forward end for the spindle model. On this basis, a real-time working algorithm was developed for the active support. It was an additional module of control-measuring application (fig. 3 - 3). To ensure the possibility of the spindle operation with replacement mass, which was subjected to excitation, it was necessary to change its fixing method (an additional bearing was used). Working principle of the automatic adjustment preload system is based on a typical regulator PID. The current displacement value from the contact-less displacement sensor was given as the input signal (fig. 2 - 6). On this basis, the control algorithm matched the lowest bearing preload values within the range allowed by the manufacturer.

It was important to carry out the settings selection procedures for the control regulator. In the case of this system they were selected by an additional experiment. It consisted in spindle activation with speed 500 $\mathrm{rev} / \mathrm{min}$, then applying harmonic excitation. Excitation was generated by the same inductor, which was used in previous tests. 
After settings selection for PID regulator, the new measurements (with control system off and on) were carried out. Test parameters were identical to those, for which the amplitude-frequency characteristics of spindle were determined. Due to the lack of a signal processing, the sampling frequency of measuring signal [2] has been significantly reduced to $900 \mathrm{~Hz}$, and one measuring cycle time was $120 \mathrm{~s}$. The measurements were carried out for two rotational speed of spindle: 500 and $1000 \mathrm{rev} / \mathrm{min}$.

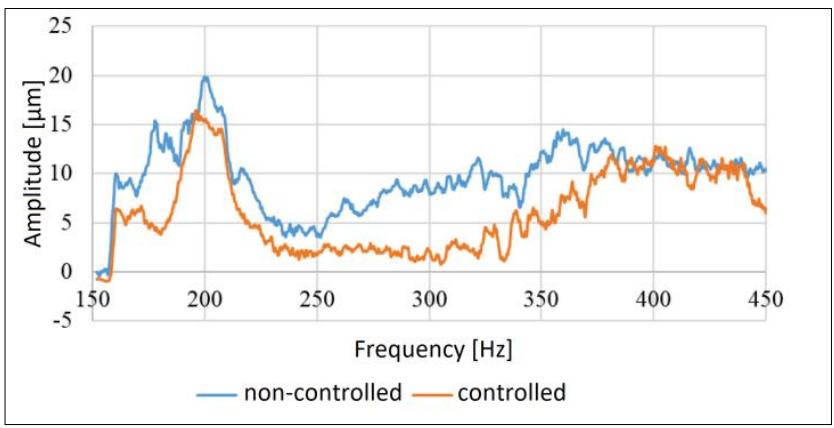

Fig. 4. Graph of the dependence of the spindle tip vibration displacement amplitude from the excitation frequency for a rotational speed of $500 \mathrm{rpm}$ during a linear sweep with a frequency of $150 \div 450 \mathrm{~Hz}$

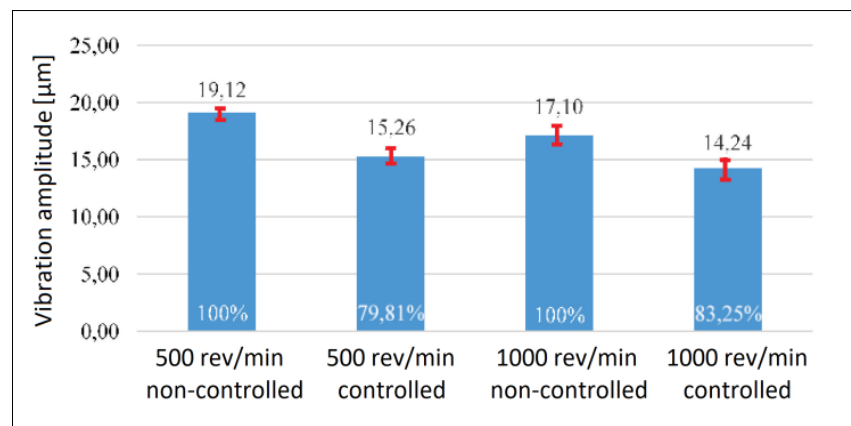

Fig. 5. Comparison of the maximum values of the spindle tip vibration amplitude ( \pm standard deviation) with its percentage decrease after using active control

For each one was carried out five repetitions (total 20 measurements). The exemplary dependency graph of vibration amplitude of the spindle forward to excitation frequency for a speed $500 \mathrm{rev} / \mathrm{min}$ is shown in fig. 4 .

Each measurement was averaged, obtaining package with 1080 samples. Further analyzes were carried out on the basis of the prepared data.

Bar graphs the maximum amplitude values of spindle tip vibration displacement for both rotational speeds with and without preload bearings control are shown in fig. 5 .

\section{Conclusions}

Tests results (fig. 5) confirm that use of an active support in the spindle system allows to reduce the vibration amplitude of the model grinding spindle model tip. It can also be noted that maximum decrease of the amplitudes shall be approx. $20 \%$ and $17 \%$ respectively for spindle rotational speed 500 and 1000 $\mathrm{rev} / \mathrm{min}$. Standard deviation for each of the series of measurements are marked by red colour on the chart. Its value is within the range $0,7 \div 1,87 \mu \mathrm{m}$, which reflects high repeatability of the measurements.

The obtained results additionally were statistically analysed in order to determine whether the used control provides statistically significant reduction in spindle tip vibration amplitude for resonance frequency. For that purpose was selected ANOVA (Analysis of Variance). It enables to determine if the factor being analysed (active bearing preload settings) has influence on the determined results (resonance amplitude of vibration displacement of spindle forward tip). For both rotational speed has been obtained statistical significance $p<0,05$ ( $p=0,004$ and $p=0,033$ respectively for speeds 500 and $1000 \mathrm{rev} / \mathrm{min}$ ). The smaller the coefficient $p$, the result assumes greater importance (spindle tip amplitude decrease). It should also be noted that with the increase of rotational speed, the coefficient $p$ increases. This could be due to limitation in the control system associated mainly with the time loop of the LabVIEW application, which sampling frequency for higher spindle rotational speeds may not be sufficient for the correct control algorithm operation.

\section{REFERENCES}

[1] Kosmol J., Lehrich K. „Model cieplny elektrowrzeciona”. Modelowanie inżynierskie. 39 (2010): 119-126, ISSN 1896-771X.

[2] Marek B., Roszkowski A., Skoczyński W., Duchiewicz T. „Wykorzystanie układu z procesorem sygnałowym do sterowania semi-aktywnymi tłumikami magnetoreologicznymi". Podstawowe problemy metrologii. PPM, 08, Sucha Beskidzka (11-14 maja 2008). Katowice: Komisja Metrologii Oddziału PAN (2008): 91-98.

[3] Sikorski J., Pawłowski W. „Innowacyjne mechanizmy wprowadzania napięcia wstępnego w układach łożysk skośnych". Mechanik. 2 (2018): 138-140, https://doi.org/10.17814/mechanik.2018.2.29. 
[4] Chen F., Liu G. "Active damping of machine tool vibrations and cutting force measurement with a magnetic actuator". International JAMT. 89, 1-4 (2017): 691-700, https://doi.org/10.1007/s00170016-9118-y.

[5] Chen J.S., Chen K.W. "Bearing load analysis and control of a motorized high speed spindle". Int J Mach Tool Manu. 45 (2005): 1487-1493, https://doi.org/10.1016/j.ijmachtools.2005.01.024.

[6] Hadi Hosseinabadi A.H., Altintas Y. "Modeling and active damping of structural vibration in machine tools". CIRP-JMST. 7 (2014): 246-257, https://doi.org/10.1016/j.cirpj.2014.05.001.

[7] Hagiu G., Dragan B. "Feed-back preload systems for high speed rolling bearings assemblies". The Annals of University Dunarea De Jos of Galati Fascicle VIII. (2004): 43-47.

[8] Harris P., Linke B., Spence S. "An energy analysis of electric and pneumatic ultra-high speed machine tool spindles". Procedia CIRP. 29 (2015): 239-244, https://doi.org/10.1016/i.procir.2015.02.046.

[9] Hwang Y.K., Lee Ch.M. "Development of a newly structured variable preload control device for a spindle rolling bearing by using an electromagnet". Int J Mach Tool Manu. 50 (2010): 253-259, https://doi.org/10.1016/j.ijmachtools.2009.12.002.

[10] Parus A., Pajor M., Hoffmann M. "Suppression of self-excited vibration in cutting process using piezoelectric and electromagnetic actuators". Advances in Manufacturing Science and Technology. 33, 4 (2009): 35-50.

[11] Vyroubal J. "Compensation of machine tool thermal deformation in spindle axis direction based on decomposition method". Precision Engineering. 36, (2012): 121-127, https://doi.org/10.1016/i.precisioneng.2011.07.013. 